\title{
Unresectable Thymic Carcinoma
}

National Cancer Institute

\section{Source}

National Cancer Institute. Unresectable Thymic Carcinoma. NCI Thesaurus. Code C148125.

A thymic carcinoma that is not amenable to surgical resection. 